\title{
FORMULASI DAN EVALUASI HAND SANITIZER SPRAY EKSTRAK ETANOL BUAH BELIMBING WULUH (Averrhoa bilimbi L)
}

\author{
Ferdy Firmansyah ${ }^{1}$, Dian Novita Wismi ${ }^{1}$ \\ Program Studi Farmasi, Sekolah Tinggi Ilmu Farmasi Riau \\ ferdyfirmansyah@stifar-riau.ac.id ${ }^{1}$, diannovitawismi@stifar-riau.ac.id ${ }^{2}$
}

\begin{abstract}
The tendency of society at this time to return to nature is by using plants as alternative medicine. In general, the use of traditional medicine is safer than modern medicine. Averrhoa bilimbi $L(A v B l)$ is known as a plant that has many activities, one of which has antibacterial activity. The use of AvBl as the main ingredient in the manufacture of hand sanitizer spray based on star fruit has flavonoid compounds that have the potential as antibacterial. The ethanol extract of the star fruit was made into hand sanitizer spray in 3 concentrations, namely F1 (10\%), F2 (12\%), and F3 (15\%). Each formula was tested for physical properties in the form of organoleptic tests, $\mathrm{pH}$ tests, homogeneity tests, and freeze and thaw stability tests for 6 cycles at $4^{\circ} \mathrm{C}$ and $40^{\circ} \mathrm{C}$ for 48 hours, respectively. The organoleptic results showed that the preparation did not change during four weeks of storage. This study found the $\mathrm{pH}$ of the preparation decreased with the addition of extract AvBl concentration, $a$ decrease also occurred from the first week to the fourth week in each formula, for F1 from $\mathrm{pH} 5.25$ to 4.88; F2 with a pH of 5.14 becomes 4.77 and F3 with a $p H$ of 4.87 becomes 4.60 . This $p H$ value is still within the specified range. The homogeneity and stability of freeze and thaw in all formulas were only homogeneous in the first week and stable in cycle 1 and cycle 2.
\end{abstract}

Keyword $\quad$ : Bilimbi fruit extract, Formulation, Hand sanitizer.

\begin{abstract}
ABSTRAK
Kecenderungan masyarakat pada saat ini untuk kembali ke alam (Back to nature) yaitu dengan cara memanfaatkan tumbuhan sebagai pengobatan alternatif. Pada umumnya, penggunaan obat tradisional lebih aman dibandingkan obat modern. Belimbing wuluh dikenal sebagai tanaman yang memiliki banyak khasiat, salah satunya memiliki aktivitas antibakteri. Pemanfaatan buah belimbing wuluh sebagai bahan utama dalam pembuatan hand sanitizer spray atas dasar buah belimbing wuluh memiliki senyawa flavonoid yang berpotensi sebagai antibakteri. Ekstrak etanol buah belimbing wuluh dibuat sediaan Hand sanitizer spray dalam 3 konsentrasi yaitu F1 (10\%), F2 (12\%) dan F3 (15\%). Tiap formula dilakukan uji sifat fisik berupa uji organoleptik, uji $\mathrm{pH}$, uji homogenitas, dan uji stabilitas freeze and thaw selama 6 siklus penyimpanan pada suhu $4^{\circ} \mathrm{C}$ dan $40^{\circ} \mathrm{C}$ masing-masing selama 48 jam. Hasil organoleptis menunjukkan bahwa sediaan tidak mengalami perubahan selama empat minggu penyimpanan. Pada pemeriksaan $\mathrm{pH}$ sediaan mengalami penurunan dengan penambahan konsentrasi ekstrak, penurunan juga terjadi dari minggu pertama ke minggu ke-empat pada masing-masing formula, untuk $\mathrm{F} 1$ dari $\mathrm{pH} 5,25$ menjadi 4,88; F2 dengan $\mathrm{pH}$ 5,14 menjadi 4,77 dan $\mathrm{F} 3$ dengan $\mathrm{pH}$ 4,87 menjadi 4,60. Angka $\mathrm{pH}$ ini masih termasuk dalam range yang ditetapkan. Homogenitas dan stabilitas freeze and thaw pada semua formula hanya homogen pada minggu pertama dan stabil pada siklus 1 dan siklus 2 .
\end{abstract}

Kata kunci : Ekstrak buah belimbing wuluh, Formulasi, Hand sanitizer.

\section{PENDAHULUAN}

Kesehatan merupakan keadaan sehat, baik secara fisik, mental, spritual maupun sosial yang memungkinkan setiap orang untuk hidup produktif secara sosial dan ekonomis menurut Undang-Undang Republik Indonesia No. 36 tahun 2009 tentang Kesehatan, kesehatan juga merupakan salah satu aspek penting yang dapat mempengaruhi kualitas hidup (quality of life) setiap individu. Salah satu 
cara yang efektif untuk menjaga kesehatan tubuh adalah dengan menjaga kebersihan, salah satunya adalah kebersihan tangan (Radji, 2010).

Tangan merupakan salah satu media utama dalam penyebaran bakteri. Oleh karena itu, perlu adanya suatu sediaan antiseptik tangan. Salah satu bentuk sediaan antiseptik yang sering digunakan untuk tangan adalah bentuk sediaan spray. Bentuk spray dipilih atas dasar sifat spray sangat praktis digunakan dan memiliki profil cepat kering sehingga mudah dipakai untuk pengguna (Iswandana et al., 2017).

Salah satu tanaman obat di Indonesia yang telah populer karena mudah diperoleh adalah belimbing wuluh (Averrhoa bilimbi L) (Wijayakusuma, 2008). Belimbing wuluh disebut juga Averrhoa bilimbi, yang termasuk dalam famili Oxalidaceae. Bagian dari tanaman ini yang dapat dimanfaatkan adalah batang, daun, bunga serta buahnya (Muhlisah, 2007). Berdasarkan penelitian (Lathifah, 2008) ekstrak etanol buah belimbing wuluh yang berpotensi sebagai antibakteri adalah flavonoid dan triterpenoid. Namun senyawa flavonoid dalam ekstrak etanol lebih dominan daripada triterpenoid.

Pada penelitian yang dilakukan oleh Ferdyani et al., (2018) ekstrak etanol buah belimbing wuluh dapat mengahambat pertumbuhan Staphylococcus aureus. Berdasarkan penelitian yang dilakukan oleh Firmansyah et al., (2018) menunjukkan bahwa gel ekstrak buah belimbing wuluh memiliki aktivitas terhadap bakteri Propionibacterium acnes. Berdasarkan hasil penelitian yang dilakukan Sukandar et al., (2018) ekstrak etanol buah belimbing wuluh memiliki aktivitas antibakteri terhadap Propionibacterium acnes, Staphylococcus epidermidis, MRSA dan MRCNS.

Berdasarkan hasil penelitian yang dilakukan oleh Rahmiati et al., (2017) . Ekstrak etanol buah belimbing wuluh dengan konsentrasi $10 \% \mathrm{~b} / \mathrm{v}, 20 \% \mathrm{~b} / \mathrm{v}, 30$ $\% \mathrm{~b} / \mathrm{v}$, dan $40 \% \mathrm{~b} / \mathrm{v}$ mampu menghambat pertumbuhan Staphylococcus aureus,

dengan rata-rata diameter zona hambat $21,6 \mathrm{~mm} ; 27,0 \mathrm{~mm} ; 31,3 \mathrm{~mm}$; dan 34,0 mm. Dan mampu menghambat pertumbuhan bakteri Staphylococcus epidermidis, dengan rata-rata diameter zona hambat $28,6 \mathrm{~mm} ; 31,6 \mathrm{~mm} ; 36,3 \mathrm{~mm}$; dan 39,0 mm.

Penelitian ini bertujuan untuk mengetahui sifat fisik sediaan hand sanitizer spray dari ekstrak buah belimbing wuluh.

\section{METODE}

Bahan utama yang digunakan pada penelitian ini adalah ekstrak buah belimbing wuluh (Averrhoa bilimbi L) yang diperoleh dari PT. Eteris Nusantara, Playen kab. Gunung kidul Yogyakarta. Penelitian ini dilaksanakan di Laboratorium Farmasetika dan Laboratorium Penelitian Sekolah Tinggi Ilmu Farmasi Riau (STIFAR) pada bulan Juli sampai Agustus 2021.

Bahan-bahan yang digunakan pada penelitian ini adalah Ekstrak buah belimbing wuluh (PT. Etaris), Aquadest (Brataco), Gliserin (Brataco), Isopropil alkohol (Brataco), Karbopol 940 (Brataco), Larutan $\mathrm{pH} 4$, larutan $\mathrm{pH} 7$, Larutan $\mathrm{pH}$ 10, Mentol (Brataco), $\mathrm{NaOH}$, Pewangi Lemon, Propilen Glikol (Brataco), Tween 80 (Brataco).

Tabel 1. Formula Sediaan

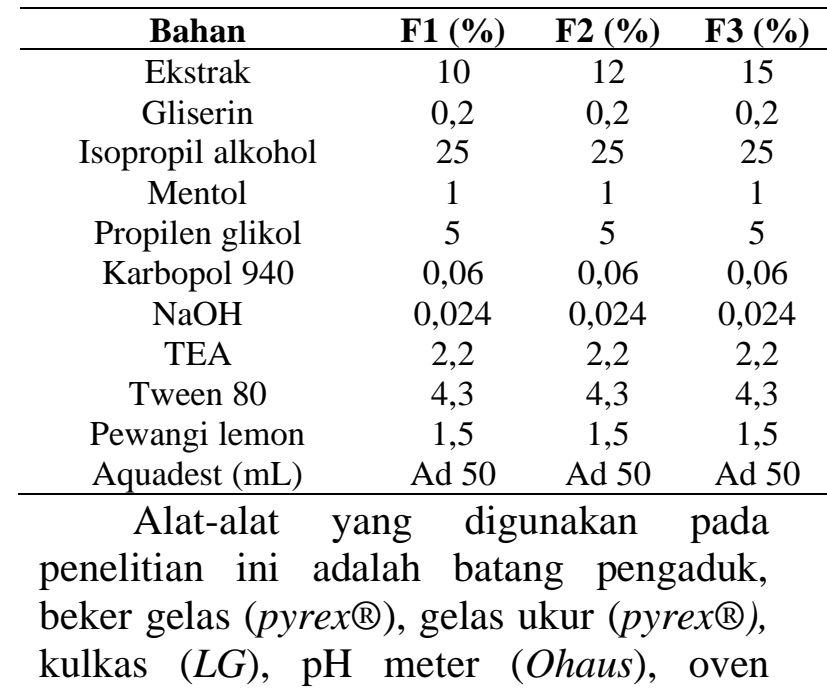


(Memmert), pipet tetes, spatel, timbangan analitik (Shimadzu).

\section{Pembuatan Hand Sanitizer Spray}

Karbopol 940 didispersikan di dalam sejumlah air pada wadah terpisah, sedangkan $\mathrm{NaOH}$ dan TEA dilarutkan dengan air. Pada tahap berikutnya, campuran karbopol 940 dengan air yang sebelumnya sudah terbentuk dicampurkan dengan $\mathrm{NaOH}$ dan TEA yang sudah dilarutkan. Selanjutnya, kedalam larutan ini, ditambahkan propilen glikol sambil diaduk hingga homogen (campuran A). pada wadah terpisah, ekstrak buah belimbing wuluh dilarutkan kedalam isopropil alkohol. Setelah ekstrak larut, ditambahkam mentol dan diaduk hingga homogen. Kemudian tambahkan gliserin dan pewangi lalu diaduk homogen (campuran B). campuran B ditambahkan kedalam campuran A, keduanya diaduk hingga homogen. Selajutnya ditambahkan solubilizing agent, yaitu Tween 80 kemudian diaduk homogen.

\section{Pengujian Sediaan Hand Sanitizer Spray Uji organoleptis}

Dilakukan dengan mendeskripsikan bentuk atau konsistensi (misalnya padat, kental, cair), warna (misalnya kuning, coklat) dan bau (misalnya aromatik, tidak berbau) (Iswandana et al., 2017).

\section{Uji pH}

Pengukuran dilakukan pada suhu ruang, masukkan $10 \mathrm{ml}$ sediaan kedalam wadah lalu celupkan alat $\mathrm{pH}$ meter kedalam wadah, catat nilai dari hasil pengukuran $\mathrm{pH}$ tersebut (Iswandana et al., 2017).

\section{Uji homogenitas}

Pemeriksaan ini untuk melihat ada atau tidaknya gumpalan atau endapan pada larutan (Depkes RI, 1979).

\section{Uji stabilitas freeze and thaw}

Sediaan disimpan pada suhu $4^{\circ} \mathrm{C}$ selama 48 jam dan suhu $40^{\circ} \mathrm{C}$ selama 48 jam, proses ini dihitung 1 siklus. Pengujian ini dilakukan selama 6 siklus. Stabilitas sediaan diamati untuk setiap siklusnya apakah ada perubahan bentuk dari sediaan (Gozali et al., 2009).

\section{HASIL}

Tabel 2. Hasil pemeriksaan organoleptis

\begin{tabular}{|c|c|c|c|c|c|}
\hline \multirow{2}{*}{ Formula } & \multirow{2}{*}{ Pemeriksaan } & \multicolumn{4}{|c|}{ Minggu ke- } \\
\hline & & 1 & 2 & 3 & 4 \\
\hline \multirow{3}{*}{ F1 } & Konsistensi & $\mathrm{C}$ & $\mathrm{C}$ & $\mathrm{C}$ & $\mathrm{C}$ \\
\hline & Bau & LM & LM & LM & LM \\
\hline & Warna & $\mathrm{CT}$ & $\mathrm{CT}$ & CT & $\mathrm{CT}$ \\
\hline \multirow{3}{*}{$\mathrm{F} 2$} & Konsistensi & $\mathrm{C}$ & $\mathrm{C}$ & $\mathrm{C}$ & $\mathrm{C}$ \\
\hline & Bau & LM & LM & LM & LM \\
\hline & Warna & $\mathrm{CT}$ & $\mathrm{CT}$ & CT & $\mathrm{CT}$ \\
\hline \multirow{3}{*}{ F3 } & Konsistensi & $\mathrm{C}$ & $\mathrm{C}$ & $\mathrm{C}$ & $\mathrm{C}$ \\
\hline & Bau & LM & LM & LM & LM \\
\hline & Warna & $\mathrm{CT}$ & $\mathrm{CT}$ & $\mathrm{CT}$ & CT \\
\hline Ket & $\begin{array}{l}\text { : Cair } \\
\text { : Lemon \& } \\
\text { : Coklat Tu }\end{array}$ & ntol & & & \\
\hline
\end{tabular}

Berdasarkan hasil pemeriksaan pada tabel 2, sediaan hand sanitizer spray untuk F1, F2 dan F3 pada minggu pertama hingga minggu keempat mendapatkan hasil yang sama berupa konsistensi cair, bau lemon dan mentol serta berwarna coklat tua.

Tabel 3. Hasil pemeriksaan $\mathrm{pH}$

\begin{tabular}{ccccc}
\hline \multirow{2}{*}{ Formula } & \multicolumn{4}{c}{ Minggu Ke- } \\
& $\mathbf{1}$ & $\mathbf{2}$ & $\mathbf{3}$ & $\mathbf{4}$ \\
\hline F1 & 5,25 & 4,96 & 4,91 & 4,88 \\
F2 & 5,14 & 4,88 & 4,82 & 4,77 \\
F3 & 4,87 & 4,66 & 4,64 & 4,60 \\
\hline
\end{tabular}

Berdasarkan tabel 3, pemeriksaan $\mathrm{pH}$ untuk F1, F2 dan F3 selama empat minggu penyimpanan secara berurutan nilai $\mathrm{pH}$ 4,88-5,25; $\mathrm{pH} 4,77-5,14$; dan $\mathrm{pH}$ 4,60-4,87. Angka ini menunjukkan bahwa $\mathrm{pH}$ sediaan hand sanitizer spray ini telah memenuhi persyaratan $\mathrm{pH}$ kulit yaitu 4,5-6,5.

Tabel 4. Hasil pemeriksaan homogenitas

\begin{tabular}{ccccc}
\hline \multirow{2}{*}{ Formula } & \multicolumn{4}{c}{ Minggu ke- } \\
& $\mathbf{1}$ & $\mathbf{2}$ & $\mathbf{3}$ & $\mathbf{4}$ \\
\hline F1 & H & TH & TH & TH \\
F2 & H & TH & TH & TH \\
F3 & H & TH & TH & TH \\
\hline
\end{tabular}

Ket : H: Homogen TH: Tidak Homogen

Hasil pemeriksaan homogenitas pada tabel 4, sediaan untuk semua formula pada minggu pertama didapatkan sediaan homogen. Kemudian pada minggu kedua 
hingga keempat sediaan menjadi tidak homogen, ini menunjukkan adanya endapan ekstrak pada sediaan. Sementara itu untuk hasil pemeriksaan freeze and thaw sediaan seperti terlihat pada tabel 5, pada semua formula di siklus pertama dan siklus kedua mendapatkan hasil yaitu sediaan stabil. Kemudian pada siklus ketiga hingga siklus keenam sediaan tidak stabil (adanya endapan ekstrak).

Tabel 5. Hasil pemeriksaan stabilitas

\begin{tabular}{ccccccc}
\hline Formula & \multicolumn{7}{c}{ Siklus ke- } \\
& 1 & 2 & 3 & 4 & 5 & 6 \\
\hline F1 & - & - & + & + & + & + \\
F2 & - & - & + & + & + & + \\
F3 & - & - & + & + & + & + \\
\hline
\end{tabular}

Ket: (-): Stabil (+): Tidak stabil

\section{PEMBAHASAN}

Zat aktif yang digunakan pada penelitian ini adalah ekstrak etanol buah belimbing wuluh yang didapatkan dari PT. Eteris Nusantara, ekstrak yang digunakan berwarna coklat tua kehitaman dan berkonsistensi kental. Ekstak etanol buah belimbing wuluh mengandung senyawa triterpenoid, saponin, tannin, flavonoid, dan alkaloid.

\section{Uji organoleptis}

Berdasarkan hasil yang didapatkan sediaan hand sanitizer spray memiliki konsistensi cair, berbau lemon \& mentol dan berwarna coklat tua pada semua formula selama waktu penyimpanan, baik pada minggu pertama sampai pada minggu terakhir (tabel 2).

\section{Uji pH}

Pengukuran $\mathrm{pH}$ bertujuan untuk memastikan kestabilan tingkat keasaman sediaan hand sanitizer spray. Sediaan topikal dengan $\mathrm{pH}$ yang terlalu asam dapat mengiritasi kulit sedangkan bila $\mathrm{pH}$ sediaan terlalu basa dapat membuat kulit menjadi kering dan bersisik (Trangggono \& Latifah, 2007). Hasil pengukuran $\mathrm{pH}$ pada tabel 4 , sediaan selama empat minggu penyimpanan menunjukkan perubahan $\mathrm{pH}$ yaitu dengan rentang $\mathrm{pH} 5,25-4,88 ; \mathrm{F} 2$ dengan rentang $\mathrm{pH}$ 5,14-4,77; dan $\mathrm{F} 3$ dengan rentang $\mathrm{pH} 4,87-4,60$. Berdasarkan hasil penelitian, $\mathrm{pH}$ sediaan semakin meningkat dengan bertambahnya konsentrasi ekstrak etanol buah belimbing wuluh. Penurunanan $\mathrm{pH}$ ini bisa jadi disebabkan karena penguapan dari komponen ektrak dan juga perbedaan konsentrasi ekstrak mempengaruhi nilai $\mathrm{pH}$ sediaan. Kandungan asam pada buah belimbing wuluh dapat juga mempengaruhi nilai $\mathrm{pH}$ sediaan, dimana buah belimbing wuluh mengandung asam organik yaitu asam format, asam asetat, asam fumarat, asam tartrat, asam malat, asam suksinat, asam oksaloasetat, asam kuinat, asam sikimat dan asam oksalat (Muchtadi et al., 2013).

\section{Uji homogenitas}

Pemeriksaan homogenitas sediaan hand sanitizer spray dilakukan dengan cara memasukkan sediaan kedalam gelas objek. Uji homogenitas dilakukan bertujuan untuk mengetahui aspek homogenitas sediaan yang telah dibuat menghasilkan kualitas yang baik (Ulaen et al., 2012). Pemeriksaan menyatakan bahwa F1, F2 dan F3 pada minggu pertama memiliki sifat homogen, hal ini ditandai dengan tidak adanya partikel pada sediaan. Sedangkan pada minggu kedua hingga minggu keempat sediaan menjadi tidak homogen (tabel 4). Hal ini disebakan karena banyaknya ekstrak yang digunakan dan lamanya waktu penyimpanan sehinggan ekstrak menjadi mengendap pada sediaan. Dapat disimpulkan bahwa semakin banyak penambahan konsistensi ekstrak maka kemungkinan kecil suatu sediaan dapat homogen.

\section{Uji stabilitas}

Pemeriksaan stabilitas dengan metode freeze and thaw dilakukan dengan cara sediaan disimpan pada suhu $4^{\circ} \mathrm{C}$ selama 48 jam didalam kulkas dan suhu $40^{\circ} \mathrm{C}$ selama 48 jam didalam oven. Tujuan dilakukannya uji ini adalah untuk melihat perubahan fase sediaan ketika disimpan dalam kondisi ekstrim. Hasil pemeriksaan freeze and thaw 
selama 6 siklus menunjukkan bahwa sediaan mengalami pemisahan berupa adanya endapan ekstrak (tabel 5). Ketidakstabilan sediaan terjadi pada siklus ke 3 hingga siklus ke 6 . pemisahan ini dapat terjadi dikarenakan perubahan suhu. Kenaikan suhu akan mempercepat reaksi kimia suatu sediaan dan suhu yang tinggi akan menyebabkan stabilitas sediaan menjadi berkurang (Gokani et al., 2012).

\section{KESIMPULAN}

Dari penelitian yang sudah dilakukan, didapatkan hasil evaluasi $\mathrm{pH} \mathrm{F} 1$ dengan rentang 5,25-4,88; F2 5,14-4,77; dan F3 4,87-4,60. Pengujian homogenitas sediaan F1, F2 dan F3 hanya homogen pada minggu pertama dan untuk stabilitas sediaan semua formula hanya stabil pada siklus 1 dan siklus 2 .

\section{UCAPAN TERIMAKASIH}

Peneliti mengucapkan terimakasih kepada pihak-pihak yang telah memberikan bantuan dan masukan dalam proses penelitian sehingga artikel dapat terselesaikan dengan tepat waktu.

\section{DAFTAR PUSTAKA}

Departemen Kesehatan RI. (1979). Farmakope Indonesia Edisi III. Jakarta : Departemen Kesehatan Republik Indonesia.

Departemen Kesehatan RI. (2009). Undang-undang Republik Indonesia No.36 Tahun 2009 Tentang Kesehatan. Jakarta: Departemen Kesehatan Republik Indonesia.

Ferdyani, S., Yuniarto, \& Savitri L. (2018). Uji Aktivitas Antibakteri Sediaan Gel Ekstrak Etanol Buah Belimbing Wuluh (Averrhoa bilimbi L) terhadap Bakteri Staphylococcus Aureus. econversion - Proposal for a Cluster of Excellence, 2(1): 30-42.

Firmansyah, F., Murrukmihadi, M. \& Anshory, H. (2018). Pengaruh HPMC Gel Ekstrak Etanol Buah Belimbing
Wuluh (Averrhoa bilimbi L) Terhadap Sifat Fisik dan Aktivitas Antibakteri, Jurnal Penelitian Farmasi Indonesia, 6(2): 76-82.

Gokani, R.H. \& Desai K.N. (2012). Stability Study: Regulatory Requirenment. International Journal of Advances in Pharmaceutical Analysis. 2: 62-67.

Gozali, D., Rusmiati, D. \& Utami, P. (2009). Formulasi dan Uji Stabilitas Ketokonazol Sebagai Antijamur Candida Albicans dan Tricophyton Mentagrophytes. 7(2): 54-58.

Iswandana, R. \& Sihombing, L.K. (2017). Formulation, Physical Stability, and In Vitro Activity Test of Foot Odor Spray with Betel Leaf Etanol Extract (Piper betle L.). Pharmaceutical Sciences and Research, 4(3): 121-131. Lathifah, Q.A. (2008). Uji Efektifitas Ekstrak Kasar Senyawa Antibakteri Pada Buah Belimbing Wuluh (Averrhoa bilimbi L) dengan Variasi Pelarut. Skripsi. Malang : Universitas Islam Negeri Malang.

Muchtadi T.R, Sugiyono., \& Ayustaningwarno, F. (2013). Ilmu Pengetahuan Bahan Pangan. Bogor: Alfabeta.

Muhlisah, F. (2007). Tanaman Obat Kelurga (TOGA). Jakarta: Penebar Swadaya.

Radji, M.. (2010). Buku Ajar Panduan Mahasiswa Farmasi dan Kedokteran. Jakarta: Buku Kedokteran EGC.

Rahmiati, A., Darmawati, S. \& Mukaromah, A.H. (2017). Daya Hambat Ekstrak Etanol Buah Belimbing Wuluh (Averrhoa bilimbi L) Terhadap Pertumbuhan Staphylococcus aureus dan Staphylococcus epidermidis Secara In Vitro. Prosiding Seminar Nasional Publikasi Hasil-Hasil Penelitian dan Pengabdian Masyarakat: 669-674.

Sukandar, E.Y., Fidrianny, I. \& Triani, R. (2018). Uji Aktivitas Antimikroba Ekstrak Etanol Buah Belimbing Wuluh (Averrhoa bilimbi L.) Terhadap 
Propionibacterium acnes, Staphylococcus epidermidis, MRSA dan MRCNS. Acta Pharmaceutica Indonesia, 39(3 \& 4): 51-56.

Trangggono, R.I. \& Latifah, F. (2007). Buku Pegangan Ilmu Pengetahuan Kosmetik. Jakarta : PT. Gramedia.

Ulaen, S., Banne, Y. \& Suatan, R. (2012). Pembuatan Salep Anti Jerawat dari
Ekstrak Rimpang Temulawak (Curcuma xanthorrhiza Roxb.). Jurnal Ilmiah Farmasi Poltekkes Manado, 3(2): 96587.

Wijayakusuma, H. (2008). Ramuan Lengkap Herbal Taklukan Penyakit. Jakarta: Niaga Swadaya. 